\title{
The Economics and Politics of Safeguards - Political Economy of the Japanese Safeguard System for Agricultural Goods -
}

\author{
Kozo Harimaya \\ Sapporo Gakuin University \\ Koichi Kagitani \\ Himeji Dokkyo University \\ Hirofumi Tominaga \\ Kobe University
}

\begin{abstract}
This paper investigates the effect of political factors on safeguards. We present a simple model to show the relationship between political factors and safeguards, and empirically examine whether the Japanese safeguard system was influenced by the political factors. Our empirical analysis shows that the Japanese safeguard system for agricultural products is not neutral to the WTO Agreement on Safeguards and it is distorted due to political reasons.
\end{abstract}

- JEL Classification: F13, D72, D73

- Key Words: safeguards, lobbying

\footnotetext{
*Corresponding address: Kozo Harimaya: Faculty of Economics, Sapporo Gakuin University, 11-banchi Bunkyodai, Ebetsu, Hokkaido 069-8555, Japan, Tel: +81-11-386-8111, Fax: +81-11-386-8115, e-mail: harimaya@sgu.ac.jp / Koichi Kagitani: Corresponding Author, Faculty of Econoinformatics, Himeji Dokkyo University, 7-2-1 Kamiohno, Himeji, Hyogo 670-8524, Japan, Tel: +81-79-223- 2211, Fax: +81-79-285-0352, e-mail: kagi@ @imeji-du.ac.jp / Hirofumi Tominaga: Graduate School of Economics, Kobe University, 2-1 Rokko-dai, Nada-ku, Kobe 857-8501, Japan, Tel: +81-78-803-7245, Fax: +81-78803-7293, e-mail: htominagadesu@ hotmail.com 


\section{Introduction}

The purpose of this paper is to investigate the effect of political factors on safeguards from the theoretical and empirical aspects. We present a simple model to examine the relationship between political factors and safeguards and empirically investigate whether the political factors influenced the Japanese safeguard system. We will show the Japanese safeguard system is distorted due to political reasons.

Though safeguards must be invoked along to the WTO rules, the invocation of safeguards will often be influenced by politicians. This is because the WTO rules leave room for bureaucratic discretion. This point is a problem of administered protection such as safeguards and antidumping duties. For example, Finger, Hall and Nelson (1982), Moore (1992a) and Hanson and Prusa (1997) found that, in their empirical studies, political factors influenced the invocation of antidumping duties in the United States. ${ }^{1}$

This perspective leads to the following legitimate question: whether the Japanese safeguard system is influenced by political factors? However, little attention has been paid to this point, ${ }^{2}$ though, in reality, problems linking politics and safeguards were observed in Japan.

On April 18, 2001, the Japanese government decided to invoke temporary emergency import restrictions on Welsh onions, raw shiitake mushrooms and tatami rushes. ${ }^{3}$ This is the first case that Japan has implemented the general safeguard measure based on the GATT Article XIX and the WTO Agreement on Safeguards. ${ }^{4}$ The main reason for this is progress in "develop-and-import schemes (kaihatsu yиnуu)" in agribusiness. Japanese companies encourage farmers in lowwage countries to grow the types of farm goods Japanese consumers want through supplying them with seeds that suit Japanese taste and with technical aid to assist

'Tharakan (1991) and Eymann and Schknecht (1993) got the similar results in EC cases.

${ }^{2}$ The reason for this is that the Japanese government has scarcely invoked safeguard measures and antidumping duties. In broader context, Anderson and Hayami (1986) empirically examined the effect of political factors on agricultural protection in East Asian countries including Japan. Harimaya and Kagitani (2006) presented a simple political economy model of trade liberalization and empirically examined whether political economy factors played a key role in the Uruguay Round agricultural tariff reductions in Japan.

${ }^{3}$ See The Daily Yomiuri, April 18, 2001.

${ }^{4}$ The special safeguard measures under the WTO Agreement on Agriculture or the WTO Agreement on Textiles and Clothing are beyond the scope of this paper. See Jackson (1997) for issues about safeguard measures. 
the farmers in growing products to Japanese quality standards. In other words, Japanese companies conduct the process of developing products in low-wage countries, mainly China and South East Asian countries. Due to this business strategy, more and more farm products have been imported from, in particular, China. For example, imports of fresh (frozen) vegetables from China in 2000 were 26.6 (8.01) times as large as that in 1990, while imports of fresh (frozen) vegetables in 2000 was 3.7 (2.2) times as large as that in 1990. Such a rapid increase in agricultural imports from China forced Japanese farmers to live in difficult circumstances. ${ }^{5}$ As a result, the demands for safeguards were growing. Many petitions for safeguards on agricultural and marine products were handed in from local governments to the central government; the number of the petitions from prefectures and that from municipalities were 31 and 1363 in 2001, respectively. ${ }^{6}$ In addition, some lawmakers affiliated with farm organizations reportedly urged bureaucrats to invoke safeguards. ${ }^{7}$ Taking account of circumstances surrounding agricultural imports, the Japanese government decided to invoke the temporary import restriction measures on the three agricultural products imported mostly from China. ${ }^{8}$

In light of these facts, the Japanese government may invoke safeguards in the near future due to changes in circumstances surrounding agricultural imports. Thus, it is meaningful to examine whether the current Japanese safeguard system is neutral to the WTO rules or distorted due political reasons. Safeguards should not be utilized for the sake of pressure groups.

The results of this paper are summarized as follows. In the theoretical analysis, we show that politicians will exert their influence strongly over bureaucrats for safeguards, when the politicians have strong leverage over the bureaucrats, when producers' loss caused by increased imports is large, and /or when a sharp rise in imports happens. Our empirical analysis shows the Liberal Democratic Party (LDP), which has connected with the agricultural sector, distorted the Japanese

\footnotetext{
${ }^{5}$ Agriculture, Forestry and Fisheries Minister Yoshio Yatsu criticized Japanese companies' develop-andimport business for impoverishing Japanese farmers and threatening food security. See The Daily Yomiuri, April 25, 2001.

${ }^{6}$ Those numbers are counted upon the number of reports and petitions under the Local Autonomy Law Article 99 and 125. See "The Number of Position Documents from Local Governments Concerning the Implementation of Safeguard Measures on Agricultural, Forestry, Fisheries Products(Nourinsuisanbutsu boueki ni tsuite no se-fu ga-do hatsudo ni kansuru chiho jichitai kara no ikensyo nado no kensu)," the Ministry of Agriculture, Forestry and Fisheries of Japan, 2001.

${ }^{7}$ For example, see The Asahi Shimbun, April 07, 2001, and The Yomiuri Shimbun, April 11, 2001.

${ }^{8}$ See also Kimura (2001) for the Japanese safeguard in 2001.
} 
safeguard system; the LDP legislators with political power may have pressure the relevant bureaucrats for safeguards and the LDP may have used the safeguard policy as an election ploy to secure farm vote.

The remainder of this paper is organized as follows. Section II.A explains the rules of safeguards briefly. Section II.B sets up the basic model and examines the effect of political factors on safeguards. The theoretical predictions in Section II.B are applied to the empirical analysis in Section III. Section IV presents the concluding remarks.

\section{Safeguard Protection}

\section{A. Rule of Safeguards}

In this subsection, to motivate the structure of our model, we discuss how safeguards differ from ordinary protectionist trade policies. Safeguards are specified under the GATT Article XIX and the WTO Agreement on Safeguards. ${ }^{9}$ These articles allow WTO members to temporarily increase tariffs or impose quantitative restrictions. ${ }^{10}$ The purpose of safeguards is to reduce the economic and social costs of structural adjustments and to make structural adjustments easier. ${ }^{11}$ In invoking safeguards, a member must observe the WTO rules.

In the implementation of a safeguard measure, a member must show the following points:

1. Increase in imports as a result of unforeseen developments and the effect of the fulfillment of obligations of the GATT, ${ }^{12}$

2. Serious injury or threat of serious injury to the domestic industry producing like or directly competitive products, ${ }^{13}$

3. The existence of the causal link between increased imports and serious injury

\footnotetext{
${ }^{9}$ In Japan, this type of a tariff increase is specified under the Customs Tariff Law Article 9 and this type of a quantitative restriction is specified under the Foreign Exchange and Foreign Trade Law and the Import Trade Control Ordinance.

${ }^{10}$ Refer to Komuro (2001) for the rule of safeguards.

${ }^{11}$ The preamble, and Article 5, 7 and 12 of the WTO Agreement on Safeguards refer to structural adjustment. Also, some scholars point out that the existence of safeguards serves as a safety valve for unpredictable and uncertain situations and thus it is necessary to promote trade liberalization. See, for example, Rosendorff and Milner (2001) for this point.

${ }^{12}$ See the GATT Article XIX.1 and the WTO Agreement of Safeguards Article 2.
} 
or threat of serious injury. ${ }^{14}$

In addition to them, in Japan, one more condition is set up under the Customs Tariff Law Article 9; "if it is deemed urgently necessary to take such measures in the interest of national economy." These requirements are investigated by the "competent authorities", which determine whether increased imports have caused or threatened to cause serious injury to domestic industries. ${ }^{15}$ In Japan, they are the ministers of the Ministry of Finance (MOF), the Ministry of Agriculture, Forestry and Fisheries (MAFF), and the Ministry of Economy, Trade and Industry (METI). In practice, some bureaucrats from these ministries investigate on safeguards. On the investigation on safeguards, the WTO Agreement on Safeguards Article 4.2 (a) states that, "the competent authorities shall evaluate ... the rate of and amount of the increase in imports of the product concerned in absolute and relative terms, the share of the domestic market taken by increased imports, changes in the level of sales, production, productivity, capacity utilization, profits and losses, and employment." We note that critical levels of each criterion and the weight given to them are not specifically identified in the WTO rules.

In addition, if the delay of the invocation of safeguards causes more serious damage to domestic industries, a member can impose temporary import restrictions even before it completes the investigation; this is called a provisional safeguard measure. ${ }^{16}$ Note, however, that the "duration of the provisional safeguard measure shall not exceed 200 days." $" 17$

Also, some restrictions are imposed on safeguard measures. If a quantitative restriction is imposed, it shall be equal to the average quantity level of imports in the last three representative years. ${ }^{18}$ The duration period of a safeguard measure shall not exceed four years and, even if it is extended, it shall not exceed eight

\footnotetext{
${ }^{13}$ See the GATT Article XIX.1 and the WTO Agreement of Safeguards Article 2.1 and 4.1. The WTO Agreement on Safeguards Article 4.1.(c) states, "in determining injury or threat thereof, a "domestic industry" shall be understood to mean the producers...whose collective output of the like or directly competitive products constitutes a major proportion of the total domestic production of those products." In Japan, as Komuro (2001) notes, "the major proportion" is defined as 50 percent.

${ }^{14}$ See the WTO Agreement of Safeguards Article 4.2 (b).

${ }^{15}$ See the WTO Agreement on Safeguards Article 3.

${ }^{16}$ The WTO Agreement on Safeguards Article 6 states, "in critical circumstances where delay would cause damage which it would be difficult to repair, a Member may take a provisional safeguard measure pursuant to a preliminary determination that there is clear evidence that increased imports have caused or are threatening to cause serious injury."

${ }^{17}$ See the WTO Agreement on Safeguards Article 6.

${ }^{18}$ See the WTO Agreement on Safeguards Article 5.1.
} 
years. ${ }^{19}$ We note that a petitioner for a safeguard will be able to calculate the approximate benefit through the invocation of safeguards.

Further, before invoking a safeguard measure, a member has to give notice to "the CONTRACTING PARTIES" and make an opportunity to consult with "the CONTRACTING PARTIES and those contracting parties having a substantial interest as exporters of the product concerned." ${ }^{20}$ The member "shall endeavour to maintain a substantially equivalent level of concession and other obligations to that existing under GATT 1994" 21 between them. If the talks break down and the safeguard measure is unilaterally invoked, the damaged export countries can take countermeasures. ${ }^{22}$ However, the export countries are unable to take any retaliatory measure for the first three years that a safeguard measure is invoked if "the safeguard measure has been taken as a result of an absolute increase in imports and that such a measure conforms to the provisions of this Agreement." ${ }^{23}$ This clause allows a member to invoke safeguards more easily than before. A member must notify to the WTO all information about their initiation of investigation, the results of the investigation, the invocation of safeguards. ${ }^{24}$

\section{B. Political Economy of Safeguards}

As Section 2.1 just explained, the distinctive features of safeguards are that the invocation of safeguards must be based on the WTO rules and that the bureaucrats of the competent authorities are the central figure in the judgment of the application and qualification of safeguards. However, the WTO rules do not specifically identify the critical level of criterions and the weight given to them, which fact implies that there is room for bureaucratic discretion in the WTO rules. Safeguards can be subject to political influence as a result.

Let us figure out how producers, politicians, and bureaucrats are related in turn from the political economy viewpoint. Producers are more likely to organize a lobby rather than consumers. This is because (i) there is a particular expense necessary to overcome the free-rider problem associated with lobbying and (ii) the costs from a safeguard measure diffuse over consumers, while the gains

\footnotetext{
${ }^{19}$ This is, what is called, a sunset provision. See the WTO Agreement on Safeguards Article 7.

${ }^{20}$ See the GATT Article XIX 2.

${ }^{21}$ See the WTO Agreement on Safeguards Article 8.1.

${ }^{22}$ See the GATT Article XIX 3.

${ }^{23}$ See the WTO Agreement on Safeguards Article 8.3.

${ }^{24}$ See the WTO Agreement on Safeguards Article 12.
} 
concentrate on producers. Thus, while organizing a lobby does not pay for consumers, producers will organize a lobby to work on politicians for safeguards. ${ }^{25}$ At the same time, politicians, who seek for political supports such as cooperation in election and political contribution, will serve lobby groups to obtain their reliable political supports. Thus, politicians will press the bureaucrats for safeguards by way of various means such as budget allocation and personnel assignment, ${ }^{26}$ and thereby the bureaucrats will invoke a safeguard measure with their discretion.

This is a potential mechanism that the invocation of safeguards is distorted due to political reasons. Here, this political mechanism is modeled simply. ${ }^{27}$ Our model analysis employs the approach similar to Grossman and Helpman (1994) in that a lobby influences a politician with political contributions and to Denzau and Munger (1986) in that a politician allocates his/her efforts to garner votes.

Consider a district in a small open economy, where a drop of the world price of a good caused a sharp rise in import of the good from $y^{S}$ to $y^{F}\left(y^{S}<y^{F}\right)$. The import surge causes damage to the producers producing the good. The loss of their profits is represented by $\Delta \pi=\pi\left(y^{S}\right)-\pi\left(y^{F}\right)$, where $\pi(\cdot)$ denotes the producers' profit. Accordingly, bureaucrats are going to judge whether to invoke a safeguard measure on the good along to the WTO rules. We assume that the policy taken as a safeguard measure is a quantitative restriction and, under the quantitative restriction, the import volume is equal to $y^{S}$. The gross profit of the producers is represented by $\pi\left(y^{S}\right)$ and $\pi\left(y^{F}\right)$ in each cases; we suppose $d \pi / d y^{F}<0$. At the same time, the safeguard measure deteriorates a consumer's utility: $\Delta u=u\left(y^{S}\right)-u\left(y^{F}\right)<0$ where $\mathrm{u}(\cdot)$ represents a consumer's utility function $\left(u^{\prime}>0, u^{\prime \prime}<0\right)$. We assume that all consumers have the same utility function.

The probability of the invocation of the safeguard will depend on two factors. The first factor is the conditions specified in the WTO Agreement on Safeguards; $r$ is the variable reflecting them. We assume that, when the import and the producers' loss become larger, $r$ increases: $\partial r / \partial y^{F}>0, \partial r / \partial \Delta \pi>0$, and as $r$ increases, the safeguard is more likely to be invoked. The second factor is a locally-elected politician's pressure on the bureaucrats. We define $h_{p}$ as the level of

\footnotetext{
${ }^{25}$ See Olson (1965) for the free rider problem associated with lobbying.

${ }^{26}$ Moore (1992b) theoretically analyzed the relationship politicians and bureaucrats in administered protection. Moore and Suranovic (1992) analyzed the reforms that reduce lobbying effectiveness and/ or tighten administered protection rules.

${ }^{27}$ See Rodrik (1995) and Helpman (1997) for comparative surveys of the political economy of trade policy literature.
} 
the politician's pressure on the bureaucrats. Thus, the probability function of the implementation of the safeguard measure is given by

$$
P=P\left(r\left(y^{F}, \Delta \pi\right), h_{p}\right),
$$

where $\partial P / \partial j>0, j=r, h_{p}$, and $\partial^{2} P / \partial j^{2}<0$.

We now consider the political relationship between the locally-elected politician and the producers or consumers. We simply assume only the producers organize a lobby to contribute money, $C_{p}$, to the politician. The producers, who are assumed to be risk neutral, maximizes as their objective:

$$
\Pi-C_{p}=P\left(r\left(y^{F}, \Delta \pi\right), h_{p}\right) \pi\left(y^{S}\right)+\left(1-P\left(r\left(y^{F}, \Delta \pi\right), h_{p}\right) \pi\left(y^{F}\right)-C_{p} .\right.
$$

We assume $\partial \Pi / \partial y^{F}>0$ so that a rise in imports motivates the producers to lobby for the safeguard.

The locally-elected politician seeks to win elections and faces the problem to allocate his/her total available efforts so as to maximize the number of votes obtained. Voters consist of unorganized constituents, i.e. the consumers, and organized constituents, i.e. the producers. The politician allots the total available efforts, $H$, to the efforts to serve the producers, $h_{p}$, and the efforts to serve the consumers, $h_{o}$. The producers, who care about their gross expected profit, will vote the politician if he/she eagerly presses the bureaucrats for the safeguard. At the same time, some consumers are informed about both the politician's behavior and its effect on their expected utility, so that they will vote the politician if he/she eagerly does a favor for them. They are assumed to be risk neutral and their individual expected utility is given by

$$
U=P\left(r\left(y^{F}, \Delta \pi\right), h_{p}\right) u\left(y^{s}\right)+\left(1-P\left(r\left(y^{F}, \Delta \pi\right), h_{p}\right)\right) u\left(y^{F}\right) .
$$

We assume $\partial U / \partial y^{F}<0$ so that a rise in imports causes the conflict concerning the safeguard between the producers and the consumers. The rest of consumers, who are uninformed, are manipulated by election campaign and thus they will vote the politician if he/she carries on a vigorous election campaign. This is why the politician wants to collect political donations for election campaign. ${ }^{28}$ We assume that most of consumers are uninformed voters. Accordingly, the locally elected 
politician's objective function will take the following form:

$$
\Omega=V_{0}\left(h_{0}, U\left(h_{p}\right)\right)+V_{p}\left(\Pi\left(h_{p}\right)\right)+\gamma C_{p} \quad \text { s.t. } \quad H=h_{o}+h_{p},
$$

where $V_{0}(\cdot)$ and $V_{p}(\cdot)$ represents the number of votes from the informed consumers and the producers, respectively, $\partial V_{0} / \partial l>0, \partial^{2} V_{0} / \partial l^{2}<0, l=h_{o}, U$, and $\partial V_{0} / \partial \Pi>0, \partial^{2} V_{0} / \partial \Pi^{2}<0$. Also, $\gamma$ denotes the number of votes which a unit of contribution buys from the uninformed voters.

The model is structured as a two-stage game. ${ }^{29}$ In stage 1 , the producers' lobby offers the politician its contingent campaign contribution schedule, which specifies the payment to the politician as a function of the effort allocated to them and is assumed to be differentiable. In stage 2, the politician decides to allocate his/her efforts, $h_{p}^{*}$, to the producers and $H-h_{p}^{*}$ to the consumers, taking the contribution schedules as given.

We will derive the politician's equilibrium effort-allocation. In the second stage, the politician maximizes equation (4), which requires the following:

$$
\frac{d \Omega}{d h_{p}}=-\frac{\partial V_{o}}{\partial h_{o}}+\frac{\partial V_{0}}{\partial U} \frac{d U}{d h_{p}}+\frac{d V_{p}}{d \Pi} \frac{d \Pi}{d h_{p}}+\gamma \frac{d C_{p}}{d h_{p}}=0 .
$$

In the absence of any campaign contribution from the producers, the politician allocates his/her efforts, $h_{p}^{o}$, to the producers and $H$ - $h_{p}^{o}$ to the consumers so as to satisfy

$$
\frac{d \Omega}{d h_{p}}=-\frac{\partial V_{o}}{\partial h_{o}}+\frac{\partial V_{o}}{\partial U} \frac{d U}{d h_{p}}+\frac{d V_{p}}{d \Pi} \frac{d \Pi}{d h_{p}}=0
$$

In the first stage, the producers' lobby sets its contribution schedule, talking account of the politician's possible reaction. Then, the lobby faces the following constraint:

$$
V_{o}\left(H-h_{p}, U\left(h_{p}\right)\right)+V_{p}\left(\Pi\left(h_{p}\right)\right)+\gamma C_{p} \geq V_{o}\left(H-h_{p}^{o}, U\left(h_{p}^{o}\right)\right)+V_{p}\left(\Pi\left(h_{p}^{o}\right)\right),
$$

\footnotetext{
${ }^{28}$ For detailed arguments about informed and uninformed voters, see Baron (1994) and Grossman and Helpman (1996).

${ }^{29}$ In modeling of lobbying, we basically follow Grossman and Helpman (1994), who drew on a menu auction model developed by Bernheim and Whinston (1986). See also Dixit, Grossman and Helpman (1997).
} 
which implies that the lobby, in offering the contribution schedule, guarantees the politician the gain which he/she could attain without any contribution. Since the lobby makes its contribution as small as possible, this inequality must be binding. Given the binding constraint, the lobby offers the contribution schedule to $\operatorname{maximize}^{30}$

$$
\Pi\left(h_{p}\right)-\frac{\left[V_{o}\left(H-h_{p}^{o}, U\left(h_{p}^{o}\right)\right)+V_{p}\left(\Pi\left(h_{p}^{o}\right)\right)\right]-\left[V_{o}\left(H-h_{p}, U\left(h_{p}\right)\right)+V_{p}\left(\Pi\left(h_{p}\right)\right)\right]}{\gamma} .
$$

Thus, at the equilibrium, the politician's effort-allocation must satisfy

$$
\frac{\partial V_{o}}{\partial h_{o}}-\frac{\partial V_{o}}{\partial U} \frac{\partial P}{\partial h_{p}} \Delta u=\frac{d V_{p}}{d \Pi} \frac{\partial P}{\partial h_{p}} \Delta \pi+\gamma \frac{\partial P}{\partial h_{p}} \Delta \pi
$$

Otherwise, the producers have an incentive to modify the contribution schedule to increase their expected profit. The second order condition is assumed to be satisfied:

$$
\frac{\partial^{2} V_{o}}{\partial h_{o}^{2}}+\left[\frac{\partial^{2} V_{o}}{\partial U^{2}}\left(\frac{\partial P}{\partial h_{p}}\right)^{2} \Delta u+\frac{\partial V_{o}}{\partial U} \frac{\partial^{2} P}{\partial h_{p}^{2}}\right] \Delta u+\left[\frac{d^{2} V_{p}}{d \pi^{2}}\left(\frac{\partial P}{\partial h_{p}}\right)^{2} \Delta \pi+\left(\frac{d V_{p}}{d \Pi}+\gamma\right) \frac{\partial^{2} P}{\partial h_{p}^{2}}\right] \Delta \pi<0 .
$$

The left-hand side of equation (5) represents the politician's marginal vote-loss from the informed consumers; the first term denotes the marginal vote-loss effect resulting from not serving for them and the second term means the marginal voteloss effect resulting from an increase in the probability of the invocation of the safeguard. The right-hand side of equation (5) represents the politician's marginal vote-gain from the producers and the uninformed consumers: the first term denotes the marginal vote-gain effect resulting from an increase in the probability of the invocation of the safeguard and the second term means the marginal vote-gain effect resulting from spending political contribution for election campaign. Thus, equation (5) implies that the politician decides his/her effort-allocation so as to equate the marginal vote-gain and loss in the electoral district.

Let us examine the conditions wherein the equilibrium politician's pressure on the bureaucrats for the safeguard measure, $h_{p}^{*}$, becomes stronger or not. First, when the marginal vote-gain effect resulting from serving the informed

\footnotetext{
${ }^{30}$ Since there are many such contribution schedules, the model here can have multiple subgame perfect equilibria. Solving a problem like this, Bernheim and Whinston (1986) and Grossman and Helpman (1994) propose a truthful contribution schedule which is a contribution schedule that reflects the true preferences of lobbies everywhere.
} 
consumers, $\partial V_{o} / \partial h_{o}$, becomes larger, $h_{p}^{*}$ decreases. This is because the size of $\partial V_{o} / \partial h_{o}$ means that the opportunity cost of the politician's serving for the producers. Second, when the marginal vote-gain effect resulting from an increase in an informed consumer's expected utility, $\partial V_{o} / \partial U$, becomes larger, $h_{p}^{*}$ decreases. This is because an increase in the probability of the invocation of the safeguard loses more their votes. Third, an increase in the loss of a consumer's utility caused by the safeguard, $\Delta u$, makes $h_{p}^{*}$ smaller because the informed consumers oppose the safeguard more intensely. Forth, an increase in the marginal vote-gain effect resulting from an increase in the producers' expected profit, $d V_{p} / d \Pi$, makes $h_{p}^{*}$ larger because serving for the producers garner their votes more easily.

Fifth, an increase in the marginal effect of the politician's pressure on the bureaucrats, $\partial P / \partial h_{p}$ makes $h_{p}^{*}$ larger if

$$
\left[\frac{d V_{p}}{d \Pi}+\gamma\right] \Delta \pi+\frac{\partial V_{o}}{\partial U} \Delta u \geq 0
$$

An increase in $\partial P / \partial h_{p}$, which implies that the politician has a stronger leverage on the bureaucrats, causes the following two opposite forces; votes and contribution from the producers increase because their expected benefit from the safeguard becomes larger, while the informed consumers are likely to vote another politician because their expected utility deteriorates. Thus, if the former effect is larger than the latter, $h_{p}^{*}$ increases.

Sixth, by totally differentiating equation (5) with $y^{F}$ constant, we prove that an increase in the producers' loss caused by increased imports makes $h_{p}^{*}$ larger if

$$
\left(\frac{d V_{p}}{d \Pi}+\gamma\right) \frac{\partial P}{\partial h_{p}}+\left(\frac{d V_{p}}{d \Pi}+\gamma\right) \frac{\partial^{2} P}{\partial r \partial h_{p}} \frac{\partial r}{\partial \Delta \pi} \Delta \pi+\frac{\partial V_{o}}{\partial U} \frac{\partial^{2} P}{\partial r \partial h_{p}} \frac{\partial r}{\partial \Delta \pi} \Delta u \geq 0 .
$$

The first term of equation (7) represents that votes and contribution from the producers increase because their expected benefit from the safeguard becomes larger. The sign of the second and third terms depend on that of $\partial^{2} P / \partial r \partial h_{p}$. $\partial^{2} P / \partial r \partial h_{p}$ denotes the effect of more suitable WTO rule-based conditions on the marginal effect of the politician's pressure; when it is positive (negative), the politician's pressure and the WTO rule-based conditions are complements (substitutes). If they are complements, an increase in $\Delta \pi$ makes $\partial P / \partial h_{p}$ stronger, so that votes and contribution from the producers increase because their expected benefit increases, while votes from the informed consumers decreases because their 
expected utility decreases. If they are substitutes, since an increase in $\Delta \pi$ makes $\partial P / \partial h_{p}$ weaker, these effects work in the opposite direction. Hence, if the vote-gain effect is larger than the vote-loss effect, an increase $\Delta \pi$ in makes $h_{p}^{*}$ larger.

Seventh, by totally differentiating equation (5) with $y^{s}$ constant, we prove that an increase in the import makes $h_{p}^{*}$ larger if

$$
\begin{gathered}
-\frac{\partial^{2} V_{o}}{\partial U \partial h_{o}} \frac{\partial U}{\partial y^{F}}-\left[\left(\frac{d V_{p}}{d \Pi}+\gamma\right) \frac{\partial P}{\partial h_{p}} \frac{d \pi}{d y^{F}}+\frac{\partial V_{o}}{\partial U} \frac{\partial P}{\partial h_{p}} \frac{d u}{d y^{F}}\right]+\left[\frac{d^{2} V_{p}}{d \Pi^{2}} \frac{\partial \Pi}{\partial y^{F}} \frac{\partial P}{\partial h_{p}} \Delta \pi+\frac{\partial^{2} V_{o}}{\partial U^{2}} \frac{\partial U}{\partial y^{F}} \frac{\partial P}{\partial h_{p}} \Delta u\right] \\
+\frac{\partial^{2} P}{\partial r \partial h_{p}}\left[\frac{\partial r}{\partial y^{F}}-\frac{\partial r}{\partial \Delta \pi} \frac{d \pi}{d y^{F}}\right]\left[\left(\frac{d V_{p}}{d \Pi}+\gamma\right) \Delta \pi+\frac{\partial V_{o}}{\partial U} \Delta u\right] \geq 0 .
\end{gathered}
$$

We assume, for simplicity, $\partial^{2} V_{o} / \partial U \partial h_{o}=0$. Thus, an increase in $y^{F}$ causes three effects. First, when $y^{F}$ increases, votes and contribution from the producers increase because their profits under the safeguard become larger, while votes from the informed consumers decrease because their utility under the safeguard becomes smaller. Secondly, since the import surge makes the producers' expected profit larger, their incentive to vote the politician becomes weaker because of $d^{2} V_{p} /$ $d \Pi^{2}<0$. At the same time, since the import surge deteriorates the informed consumers' expected utility, they are more likely to vote another politician because of $\partial^{2} V_{o} / \partial U^{2}<0$. The third effect depends on the sign of $\partial^{2} P / \partial r \partial h_{p}$. When it is positive, an increase in $y^{F}$ makes $\partial P / \partial h_{p}$ stronger and thereby the probability of the implementation of the safeguard becomes larger, so that politicians gain more votes and contribution from the producers, but loses more votes from the informed consumers. When it is negative, an increase in $y^{F}$ makes $\partial P / \partial h_{p}$ weaker and these effects are reversed. In sum, when the vote-gain effect is larger than the vote-loss effect, an increase in $y^{F}$ makes $h_{p}^{*}$ larger.

These findings are now summarized in the following proposition.

Proposition: If the invocation of a safeguard measure on a good is at issue, a politician pressures more strongly the relevant bureaucrats for the safeguard under the following conditions; (i)when the marginal vote-gain effect resulting from serving for informed consumers becomes smaller; (ii)when the marginal vote-gain effect resulting from an increase in a consumer's expected utility becomes smaller; (iii)when the loss of a consumer's utility caused by the safeguard is smaller; (iv)when the marginal vote-gain effect resulting from an increase in the producers' expected profit from the safeguard becomes larger; (v)when the marginal effect of the politician's pressure on the bureaucrats 
becomes stronger and condition (6) holds; (vi)when the producers' loss caused by increased imports increases and condition (7) holds; and/or (vii) when the import of the good increases rapidly and condition (8) holds.

The fifth, sixth and seventh results are ambiguous. However, we note that the following facts are observed in reality: (i) the costs from safeguards diffuse over consumers, while the gains concentrate on producers; (ii) most voters are uninformed about safeguards; and (iii) producers are a handful of voters. Hence, the vote-gain effect could well be larger than the vote-loss effect. If this is the case, a politician pressures more strongly the relevant bureaucrats for safeguards when the politician's influence on the bureaucrats becomes stronger, when producers' loss caused by increased imports becomes larger and/or when a sharp raise in imports happens.

\section{Empirical Analysis}

\section{A. Framework of Empirical Analysis}

This section examines the current Japanese safeguard system is based on the WTO rules or influenced by domestic political factors. However, we are confronted by one difficulty; we cannot follow the previous studies' approach; among safeguard-investigations, what factors were effective over safeguard decisions by the competent authorities. This is because samples are inevitably scarce; the Japanese government has investigated for safeguards only four products: Welsh onions, fresh shiitake mushrooms, tatami rushes and towels. ${ }^{31}$ To overcome this difficulty, we focus attention on a recent development in the Japanese safeguard system: the monitoring system for collecting information on safeguards.

The safeguard monitoring system was prepared by the Ministry of Agriculture, Forestry and Fisheries (MAFF) in January 2001. ${ }^{32}$ This system is aim to collect constantly any information for safeguards about the specified agricultural and marine products. The system consists of Level 1 and Level 2. The targets of Level 1 are investigated under a normal monitoring system; their data for safeguards are collected quarterly or at a cropping season. The monitored products under Level 1 are garlic, eggplants, dried shiitake mushrooms, skipjacks, chipboards and sweetened preparations. The targets of Level 2 are investigated under the emergent monitoring system; their monthly data for safeguards are collected. The monitored 
goods under Level 2 are Welsh onions, fresh shiitake mushrooms, tatami rushes, tomatoes, green-peppers, onions, brown seaweeds, lumbers and eels. Thanks to this system, safeguards will be invoked on the monitored goods promptly after circumstances surrounding them meet the conditions specified in the WTO Agreement on Safeguards.

In light of the aim of the safeguard monitoring system, the MAFF may have selected the target goods, which had prospects of satisfying the conditions in the WTO rules in the near future ${ }^{33}$ the screening process seemed to be rule-based. However, the screening process may have been influenced by political factors. Noting that the targets of the safeguard monitoring system have a high chance of invocation of safeguards, ${ }^{34}$ we naturally consider that, since farmers hoped their farm goods were selected as the targets, politicians might have pressed the senior officials of the MAFF to obtain their political supports. Hence, it will be justified to take up the monitoring system as an alternative setting for our empirical research.

Moreover, a vegetable seem to be suited to our sample in light of the following three reasons. First, vegetables, which account for 53\% of the targets of the safeguard monitoring system, are the most typical targets. Focusing only on a vegetable will promise to eliminate the effect of any difference from a category of products on the MAFF's selection. ${ }^{35}$ Second, there is a rapid increase in imports of vegetables in Japan, which implies that various vegetables can be subjects of safeguards in the near future. Third, the data required for our analysis is easilyavailable because the detailed data by item has been provided on a regular basis by the MAFF.

As a result, we examine why only several vegetables were selected as the targets

\footnotetext{
${ }^{31}$ The Japan Towel Industrial Association filed a petition for safeguards on February 26, 2001 and the Ministry of Economy, Trade and Industry (METI) initiated the investigation for safeguards on towels. After two successive extensions of the investigation, the METI made a negative decision about the safeguard measure on imported towels on April 02, 2004.

${ }^{32}$ See "Preparing for the monitoring system for collecting information on Safeguards (Se-fu ga-do ni kakaru jyoho syusyu monitaringu taisei no seibi ni tsuite)," the Ministry of Agriculture, Forestry and Fisheries of Japan, January 2001.

${ }^{33}$ The Japanese government initiated the safeguard-investigation on Welsh onions, fresh shiitake mushrooms, and tatami rushes in December 22, 2000.

${ }^{34}$ In fact, the MAFF requested the MOF and the METI to initiate investigations for safeguards on brown seaweeds and eels on March 14, 2001

${ }^{35}$ For example, in investigating the increase in import of tatami mats, the government used the inaccurate trade statistics. Since some customs offices classified tatami mats as an item in an incorrect commodity classification, the Ministry Finance corrected the classification from September 1999. Thereby the trade statistics showed a sharp increase in the imports of tatami mats from 1998 to 1999. See The Asahi Shimbun, November 16, 2001.
} 
of the safeguard monitoring system. With regard to our data set, we sampled 34 vegetables. ${ }^{36}$ Our sample basically consists of the vegetables about which all the data required for our analysis is available. However, we excluded some vegetables from our sample. Firstly, we excluded some vegetables such as matsutake mushrooms, capsicums and Brussels sprouts, since their domestic production was low. This is because their domestic production would have little impact on the national economy. ${ }^{37}$ Secondly, we omit potatoes and sweet potatoes because the imports of them are severely restricted; imported potatoes, which can be seed potatoes, must go through strict quarantine because of the prevention of epidemic. Lastly, we excluded strawberries, water melons and melons, which are generally considered as fruits, because the intensity of competition against foreign-grown ones will not be so keen due to their product differentiation.

Our regression analysis method is a cross-section analysis with political factors and the WTO rule-based factors, which allows us to find what kind of factors dominated the MAFF's selection of the targets of the safeguard monitoring system. If the political factors are statistically significant, we can state that the Japanese safeguard system is distorted by political factors, while, if not, the Japanese safeguard system is neutral to the WTO rules.

\section{B. Structure of Estimated Equations}

In this subsection, we consider the dependent and independent variables in our empirical analysis. The dependent variable shows whether a vegetable was selected as the monitored good by the MAFF or not. Such a dependent variable is a qualitative variable, which takes either 0 or 1 . Define $1(0)$ as the vegetable selected (not selected) as the target. Since the dependent variable is discrete, it is appropriate to use a non-linear probability model. We use a probit analysis.

The independent variables fall into two categories: the WTO rule-based conditions and political factors. On the WTO rule-based condition, we have no

\footnotetext{
${ }^{36}$ Our samples are the following vegetables; carrots, edible burdocks, lotus roots, lettuces, Welsh onions, celeries, cauliflowers, broccoli, pumpkins, eggplants, tomatoes, green peppers, kidney beans, peas, green soybeans, aroid, onions, cucumbers, Chinese cabbages, cabbages, radishes, turnips, yams, spinaches, sweet corns, fresh shiitake mushrooms, bamboo shoots, garlic, green chives, asparagus, ginger root, okra pods, shallots, and parsley.

${ }^{37}$ We excluded the vegetables the average output of which in 1997-2000 is less than 1,000 ton. For example, the amount of production of some vegetables in 2000 are as follows: matsutake mushrooms, $181 \mathrm{t}$; capsicums, 187 t; Brussels sprouts, 340 t; onions, 1247,000 t; cabbages, 1449,000 t; radishes, $1876,000 \mathrm{t}$.
} 
means of knowing the criteria for the targets of the safeguard monitoring system. However, in light of the aim of the safeguard monitoring system, we reasonably consider that circumstances surrounding the monitored goods met some of the WTO rule-based conditions. We evaluate an increase in import of a vegetable and the loss of farmers producing a vegetable, which are the fundamental conditions in the WTO Agreement on Safeguards. As an explanatory variable, we use the percent changes of import of a vegetable $(I M G)$ and the difference of sales volume of a vegetable between two years. ${ }^{38}$ Furthermore, the agreement specifies that the share of the domestic market taken by increased imports is one of the conditions to be investigated. Accordingly, we include the import share in 2000 (IMS). These expected signs are all positive.

Next, we consider the independent variables for political factors. Since we have no data on politicians' activities for safeguards, we should refer to Proposition in the last section to consider the factors which influence a politician's action for safeguards. Before doing that, two points should be noted about the political factors in Japan. First, we concentrate on the Liberal Democratic Party (LDP), which led the coalition government at the time. This is because many Diet members of the Liberal Democratic Party (LDP) have been backed with farmers. ${ }^{39}$ In particular, the LDP legislators belonging to LDP farm committees can exercise their influence over the MAFF. ${ }^{40}$ Under the LDP rule, the bills drafted by ministries and agencies need to receive the endorsement of the LDP Policy Research Council and LDP policy groups before the bills are introduced into the Diet. As a result, the LDP legislators belonging to LDP committees can exercise their influence over bureaucrats. For example, Teramachi (2004) pointed out the influence of lawmakers affiliated with farm organization on the Japanese provisional safeguards in 2001. Second, we also concentrate on political factors in the top three prefectures in production. This is because only farmers in the region producing vegetables in large quantity strongly lobby for safeguards to put the brakes on the imports of them and accordingly only politicians elected from the region eagerly exercised their influence over the bureaucrats for the safeguards. Thus, we propose the following independent variable; ${ }^{41}$

\footnotetext{
${ }^{38}$ The sales volume of each vegetable is calculated by the price times the shipping volume.

${ }^{39}$ See Aurelia (2000) and Davis (2003) for this topic.

${ }^{40}$ The LDP lawmakers affiliated with farm organizations are called "norin zoku."

${ }^{41}$ See also Harimaya and Kagitani (2006) for this type of independent variable.
} 


$$
P O L_{i}=\sum_{j=1}^{\jmath} S_{i j} P V_{j},
$$

where the subscript $i$ and $j$ represents a vegetable and a prefecture, respectively. $S_{i j}$ means the prefecture $j$ 's share of shipping volume of vegetable $i$. $P V_{j}$ denotes a political factor in prefecture $j . P O L_{i}$ is the weighted average of variable $i$ about political factors associated with politicians' action for safeguards in the top three prefectures producing vegetable $i$.

We now consider the independent variables about political factors on the basis of Proposition. According to Proposition, a politician with strong political power will pressure the bureaucrats more strongly for safeguards. Hence, the LDP legislators who have a voice over agricultural policies will work on behalf of farmers more eagerly to obtain their political supports. Accordingly, we consider two independent variables about LDP legislators. The first variable focuses on how many times LDP Lower House members in a prefecture had been elected. This is because the politicians who have won elections many times are leading politicians in the LDP. We use as $P V_{j}$ the total number of times of winning an election by the LDP House of Representatives in a prefecture $(P O L 1)$ or the number of the LDP House of Representatives in a prefecture who had been elected more than five times (POL2). The second variable focuses on the LDP legislators in a prefecture belonging to the LDP farm committees. We use the number of the LDP legislator belonging to the LDP Comprehensive Agricultural Policy Research Council or the LDP Agricultural and Marine Products Trade Policy Council (POL3). The expected signs for POL1, 2, and 3 are positive.

Moreover, Proposition says that politicians will pressure the relevant bureaucrats for safeguards more strongly if working on behalf of farmers garner their votes more efficiently. Thus, we also use as $P V_{j}$ the share of votes for the LDP in the Lower House election in 2000 times the ratio of the number of farmers to the number of labors in a prefecture $(P O L 4)$, which represents farmers' vote for the LDP in a prefecture. The expected sign for POL4 is positive, since the LDP lawmakers elected from farm areas count on political support from farmers. In addition, it may be interesting to note the fact that it was often reported that the Japanese safeguard measures in April 2001 might be invoked in advance of the Upper House election to secure farm vote. This fact implies that the LDP may have used the safeguard monitoring system to win the coming Upper House election. Thus, we include the share of votes for the LDP in the Upper House election in 
1998 times the ratio of the number of farmers to the number of labors (POL5), the expected sign for which is positive.

We do not include these variables simultaneously in the equations because of the high degree of multicollinearity among them. Further, in light of Proposition, three points should be noted. First, politicians will pressure more strongly the relevant bureaucrats for safeguards when an import surge causes serious damage to farmers. Thus, the coefficient on farmers' loss may reflect this political effect as well as the effect of the WTO rules. Second, a rapid increase in imports will induce politicians to pressure the bureaucrats for safeguards, which effect may influence the coefficient on increased imports. Third, we do not examine the effect of consumers' aversion toward safeguards, data about which is not available. However, since the loss of a consumer's utility resulting from safeguards will be negligible small and most consumers are uninformed about safeguards, this will not cause trouble for our analysis.

\section{Estimated Results}

Tables 1 and 2 show our probit estimation results. Let us check the estimation results only with the WTO rule-based conditions: the column $(0)$ in both tables. Since we cannot know what kinds of data the MAFF investigated to select the target goods of the safeguard monitoring system, we referred to in the Japanese government survey on the safeguards in $2001 .^{42}$ We use the percent changes of import of a vegetable from 1997 to $2000\left(I M G_{1}\right)$ and the amount of difference of sales of a vegetable between 1997 and 2000 (LOS). The import growth variable in Table 1 is negatively and not significant, which is different from our expectation. This result may show that the MAFF did not attach importance to a sharp rise in imports. However, the MAFF may have put weight on another import growth. Alternatively, we use the percent changes of import of a vegetable from 1999 to $2000\left(I M G_{2}\right)$ and have the estimation results in Table 2. Though the import variable is not significant, the expected positive sign is estimated. This result indicates that the MAFF might have drawn attention to not a mid-and-long term import growth but short-term one. In addition, the import surge just before starting of the safeguard monitoring system might have induced politicians to exert their influence over the MAFF (see Proposition). In what follows, to make assessment

\footnotetext{
${ }^{42}$ See "Summary of major indexes in the government's safeguard survey (Se-fu ga-do seifu tyousa ni okeru syuyo shihyo no gaiyo)," the Ministry of Agriculture, Forestry and Fisheries of Japan, October 2001.
} 
Table 1. Probit Estimation of Decision Making for Safeguards; Case I

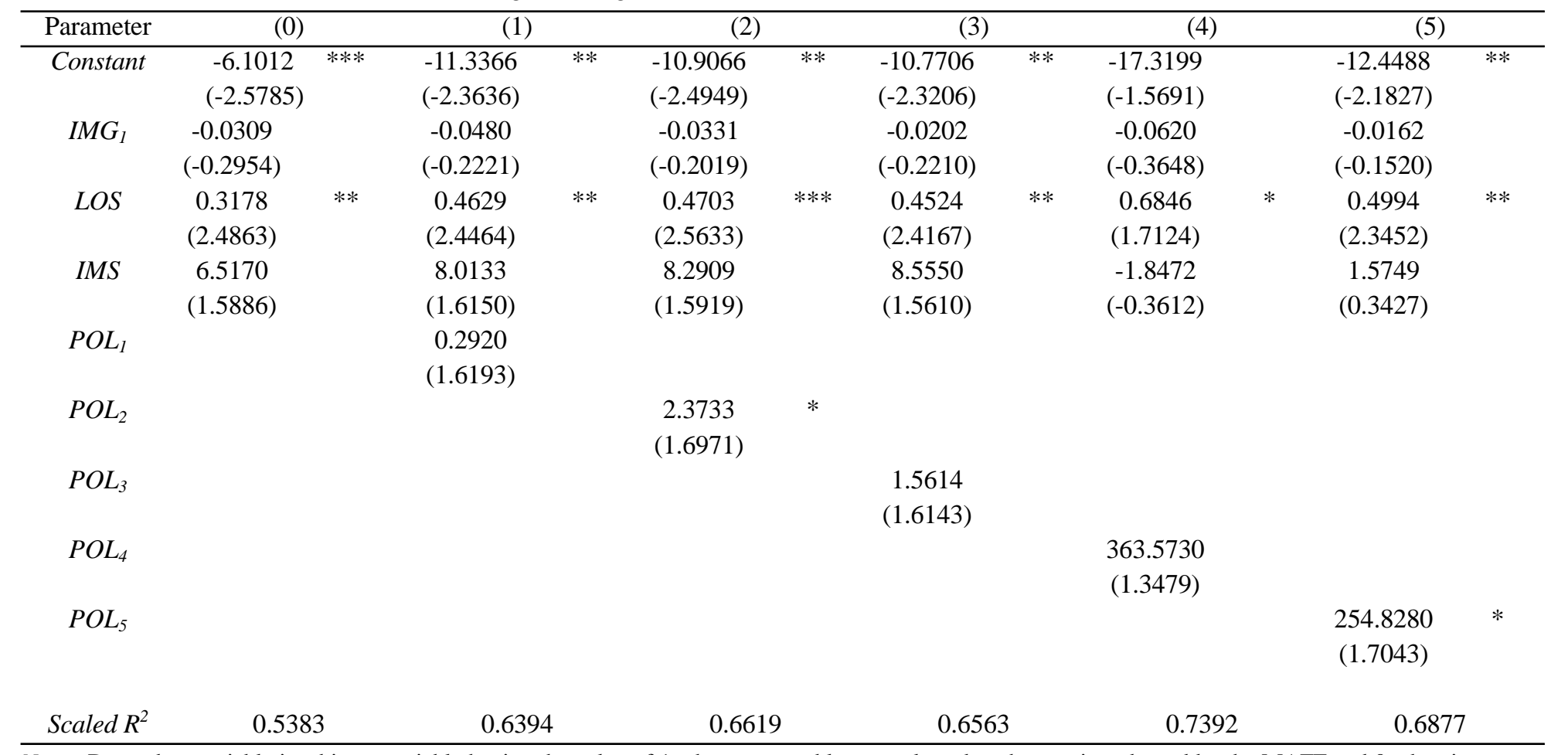

Notes: Dependent variable is a binary variable having the value of 1 when a vegetable was selected as the monitored good by the MAFF and 0 when it was not selected. $I M G_{1}$ is the percent changes of import of a vegetable from 1997 to 2000; LOS is the amount of difference of sales of a vegetable between 1997 and 2000 ; $I M S$ is the import share of a vegetable in 2000; $P O L_{1}$ represents the total number of times of winning an election for LDP House of Representative members; $P O L_{2}$ represents the number of the LDP House of Representative members who had been elected more than five times; $P O L_{3}$ represents the number of the LDP legislators belonging to the LDP Comprehensive Agricultural Policy Research Council or the LDP Agricultural and Marine Products Trade Policy Council; $P O L_{4}$ represents farm vote for the LDP in the Lower House election in 2000; $P O L_{5}$ represents farm vote for the LDP in the Upper House election in 1998. $* * *, * *$ and $*$ stand for significance at the $1 \%, 5 \%$ and $10 \%$ levels. 
Table 2. Probit Estimation of Decision Making for Safeguards; Case II

$(t$-statistics in Parentheses)

\begin{tabular}{|c|c|c|c|c|c|c|c|c|c|c|c|c|}
\hline \multirow{2}{*}{$\frac{\text { Parameter }}{\text { Constant }}$} & \multicolumn{2}{|l|}{ (0) } & \multicolumn{2}{|l|}{ (1) } & \multicolumn{2}{|l|}{ (2) } & \multicolumn{2}{|l|}{ (3) } & \multicolumn{2}{|l|}{ (4) } & \multicolumn{2}{|c|}{ (5) } \\
\hline & -6.5582 & *** & -11.7610 & $* *$ & -11.4093 & $* *$ & -11.7970 & $* *$ & -12.3171 & ** & -13.2126 & $* *$ \\
\hline & $(-2.6111)$ & & $(-2.3543)$ & & $(-2.4817)$ & & $(-2.3587)$ & & $(-2.0234)$ & & $(-2.1002)$ & \\
\hline \multirow[t]{2}{*}{$I M G_{2}$} & 0.0173 & & 0.0164 & & 0.0060 & & 0.0105 & & -0.0615 & & 0.0291 & \\
\hline & $(0.0482)$ & & $(0.0436)$ & & $(0.0165)$ & & $(0.0284)$ & & $(-0.2255)$ & & $(0.0974)$ & \\
\hline \multirow[t]{2}{*}{$L O S$} & 0.3141 & $* *$ & 0.4528 & $* *$ & 0.4641 & $* *$ & 0.4760 & $* *$ & 0.4720 & $* *$ & 0.5075 & $* *$ \\
\hline & $(2.4854)$ & & (2.4909) & & $(2.5363)$ & & $(2.3513)$ & & $(2.2172)$ & & $(2.2171)$ & \\
\hline \multirow[t]{2}{*}{$I M S$} & 7.5066 & $*$ & 9.3080 & $*$ & 9.6962 & $*$ & 9.8100 & $*$ & 0.9879 & & 2.8309 & \\
\hline & (1.7773) & & $(1.7825)$ & & $(1.7411)$ & & (1.6928) & & $(0.2121)$ & & $(0.6552)$ & \\
\hline \multirow[t]{2}{*}{$P O L_{1}$} & & & 0.2816 & & & & & & & & & \\
\hline & & & $(1.5763)$ & & & & & & & & & \\
\hline \multirow[t]{2}{*}{$\mathrm{POL}_{2}$} & & & & & 2.3070 & $*$ & & & & & & \\
\hline & & & & & (1.6860) & & & & & & & \\
\hline \multirow[t]{2}{*}{$\mathrm{POL}_{3}$} & & & & & & & 1.7003 & $*$ & & & & \\
\hline & & & & & & & (1.6994) & & & & & \\
\hline \multirow[t]{2}{*}{$\mathrm{POL}_{4}$} & & & & & & & & & 224.9020 & & & \\
\hline & & & & & & & & & (1.4958) & & & \\
\hline \multirow[t]{2}{*}{$\mathrm{POL}_{5}$} & & & & & & & & & & & 257.1490 & $*$ \\
\hline & & & & & & & & & & & (1.6653) & \\
\hline
\end{tabular}

0.5025

0.5959

0.6195

0.6385

0.6288

0.6483

Notes: Definition of independent and dependent variables are identical to those in Table 1 except for $I M G_{2} . I M G_{2}$ is the percent changes of import of a vegetable from 1999 to 2000.

$* * *, * *$ and $*$ stand for significance at the $1 \%, 5 \%$ and $10 \%$ levels. 
more properly, we will discuss the estimated results of both tables.

The farmers' loss variables $(L O S)$ in both tables are positively and significantly correlated with the MAFF's selection at the 5\% level. This result proves that the MAFF, according to the WTO rules, regarded the vegetables whose producers have been seriously injured as the subject goods for safeguards. Also, this result indicates that an increase in farmers' loss may have induced politicians to exert their influence over the MAFF in order to obtain political support from farmers (see Proposition).

The import share variables (IMS) in both tables are positively and significantly correlated with the MAFF's selection at the $10 \%$ and above-level. This result shows that the MAFF may have considered a higher import penetration had impact on domestic farmers.

Next, we check the estimation results with both the WTO rule-based conditions and the political factors. On the independent variables about the WTO rule-based conditions, the estimated results in both tables are almost the same as those only with the WTO rule-based conditions. Accordingly, we focus only on the effect of political variables on the MAFF's decisions on the safeguard monitoring system. In accordance with the variety of the political variables, our results are numbered from (1) to (5). All the independent variables about LDP lawmakers' influence over the MAFF, POL1-3, in both Tables have the expected positive signs and are significantly correlated with the MAFF's selection at the $10 \%$ and above-level. These results indicate that the LDP legislators with political clout may have exerted their influence over the MAFF. We note that the political muscle of locally elected politicians played an important role in the Japanese safeguard system.

Furthermore, although the independent variable for farm vote in the Lower House election, POL4, in both tables is not significant, the expected positive estimates are estimated. This result implies that the LDP lower house members elected from farm areas might not have attempted to secure farm vote in the next election. The independent variables for farm vote in the Upper House election, $P O L 5$, in both tables are positively and significantly correlated with the MAFF's selection at the $10 \%$ level. This result shows LDP legislators may have spent their energy to secure farm vote to lead the LDP to victory in the impending election. Indeed, as the mass media reported, the LDP may have used the safeguard policy as an election ploy to secure farm vote.

Our discussion of the regression results indicates that the political factors distorted the Japanese safeguard system. In order to verify this point, we examine 
the hypothesis that the coefficients on all political variables are zero by using the likelihood test. The null hypothesis is rejected at the 5\% level in results (2)-(5) in both tables and at the $10 \%$ level in result (1) in both tables. In addition, Scaled $R^{2}$ of the model with both the WTO rule-based conditions and political factors is improved compared with that of the model only with the WTO rule-based conditions. Hence, we can state the LDP lawmakers exercised their political influence over the bureaucrats for safeguards to secure political support from farmers. Our results indicate that the Japanese safeguard system is not neutral to the WTO rules and that the economic groups who could bring strong pressure to politicians are more likely to get benefits from safeguards than the economic groups who could not. This implies that the Japanese safeguard system is problematic from the stand point of fairness and social welfare.

\section{Conclusion}

In general, a safeguard measure is considered to be less influenced by political factors because it is subject to the WTO rules and the relevant bureaucrats, who are not directly influenced by interest group, investigate and judge the application and qualification of safeguards. However, their judgment can be distorted due to political reasons. This is because (i) there is room for bureaucratic discretion in the WTO rules; and (ii) politicians, who want to secure political supports from specific industries, can exert their influence on the bureaucrats by various means such as budget allocation. This paper has investigated the effect of political factors on the safeguards from the theoretical and empirical aspects.

Firstly, our theoretical analysis shows that politicians press more strongly the relevant bureaucrats for safeguards to gain political supports from producers when the vote-gain effect from the invocation of the safeguards are larger than the voteloss effect in their districts. In particular, when a politician has strong leverage over the bureaucrats, when producers' loss caused by increased imports is large, and /or when a sharp rise in imports happens, the politician will strongly urge the bureaucrats to invoke the safeguard.

Secondly, our empirical analysis proves that the Japanese safeguard monitoring system was influenced by the political factors derived from our theoretical analysis. We confirm that politicians' political power played an important role in the Japanese safeguard system, and Japanese safeguard policy was used as an election ploy to secure farm vote. 
Our empirical result show that the Japanese safeguard system is not neutral to the WTO rules and is problematic from the stand point of fairness and social welfare. Thus, it should be reviewed and designed in order not to be influenced by political factors. This conclusion may lead us to argue that an independent agency for administered protection such as the International Trade Commission (ITC) in the U.S. should be established in Japan. But, some empirical studies, e.g., Moore (1992a), show that even ITC was influenced by political factors. Hence, we should carefully examine the costs and benefits of establishing such an independent agency. In order to discuss this point, we should analyze how the relevant bureaucrats, who are self-interested, interact with politicians and how they govern the safeguard system. This point remains a future task.

\section{Acknowledgements}

A previous version of this paper was titled "The economics and politics of administered protection" and was presented in the 2003 Fall Meeting of the Japanese Economic Association held at Meiji University. We wish to thank Shoji Nishijima, Norio Komuro, Morihiro Yomogida, Akio Namba and Kenji Fujiwara for their helpful comments. This version was presented at a SFU seminar. We also thank, Steve Easton, Alex Karaivanov and seminar participants for helpful discussions and an anonymous referee for helpful suggestions. All remaining errors are our own responsibility. This version was completed while Kagitani was visiting the Department of Economics, Simon Fraser University. He is grateful to its support.

Received 06 December 2007, Revised 20 April 2008, Accepted 28 April 2008

\section{Appendix}

The data on imports of vegetables except for Shiitake mushrooms were from Statistics on Plant Quarantine, Statistics and Information Department, The Ministry of Agriculture, Forestry and Fisheries of Japan, and the data on imports of Shiitake mushrooms were from Foreign Trade Statistics, The Ministry of Finance.

The prefectural data on each vegetable's shipment were obtained from Statistical Yearbook of Ministry of Agriculture, Forestry and Fisheries, Statistics and Information Department, The Ministry of Agriculture, Forestry and Fisheries of 
Japan; and Production Circumstances of Special Local Vegetables (Chiiki Tokusan Yasai no Seisan Jyokyo), Vegetable Production and Marketing Division, Agricultural Production Bureau, The Ministry of Agriculture, Forestry and Fisheries of Japan. The data on the domestic price of each vegetable were from Annual Report of the Metropolitan Central Wholesale Market (Tokyo Chuo Oroshiuri Shijyo Nenpo), Metropolis of Tokyo.

The data on the number of labors and farmers in each prefecture were obtained from Japan Statistical Yearbook, Statistical Bureau/Statistical Research and Training Institute, The Ministry of Public Management, Home Affairs, Posts and Telecommunications and Statistical Yearbook of Ministry of Agriculture, Forestry and Fisheries, Statistics and Information Department, The Ministry of Agriculture, Forestry and Fisheries of Japan, respectively.

The data on members of the House of Representatives was obtained from Handbook of Politics (Seiji Handbook), The Center for Political and Public Relations Inc. The data on elections was from Japan Statistical Yearbook, Statistical Bureau/Statistical Research and Training Institute, The Ministry of Public Management, Home Affairs, Posts and Telecommunications, Japan. The data on the LDP legislator belonging to the LDP farm committee were from Teramachi (2003) p.857.

\section{References}

Abbott, P. C. and Paarlberg, P. L. (1998), "Tariff Rate Quota: Structural and Stability Impacts in Growing Markets", Agricultural Economics, Vol. 19, pp. 257-267.

Anderson, K. and Hayami, Y. (1986), "The Political Economy of Agricultural Protection; East Asia in International Perspective", Sydney: Allen \& Unwin in Association with the Australia-Japan Research Center, Australian National University.

Aurelia, G. (2000), The Politics of Agriculture in Japan, London: Routledge.

Baron, D. P. (1994), "Electoral Competition with Informed and Uninformed Voters", American Political Science Review, Vol. 88, pp. 33-47.

Bernheim, B. D. and M. Whinston. (1986), "Menu Auctions, Resource Allocation, and Economic Influence", Quarterly Journal of Economics, Vol. 101, pp. 1-31.

Davis, C. L. (2003), Food Fights over Free Trade, Princeton, NJ, Princeton University Press.

Denzau, T. A. and M. C. Munger (1986), "Legislators and Interest Groups; How Unorganized Interests Get Representative", American Political Science Review, Vol. 88, pp. 33-47.

Dixit, A., G. M. Grossman and E. Helpman (1997), "Common Agency and Coordination: 
General Theory and Application to Government Policy Making", Journal of Political Economy, Vol. 105, pp. 752-769.

Eymann, A. and Schuknecht, L. (1993), "Antidumping Enforcement in the European Community", in J. M. Finger. ed., Antidumping - How It Works and Who Gets Harm -, Michigan, University of Michigan Press, pp. 221-239.

Finger, J. M. and Nelson, D. R. (1982), "The Political Economy of Administered Protection", American Economic Review, Vol. 72, pp. 452-466.

Grossman, G. M. and E. Helpman (1994), "Protection for Sale", American Economic Review, Vol. 84, pp. 833-850.

Grossman, G. M. and E. Helpman (1996), "Electoral Competition and Special Interest Politic," Review of Economic Studies, Vol. 63, pp. 265-286.

Hansen W. L. and Prusa, T. J. (1997), "The Economics and Politics of Trade Policy: an Empirical Analysis of ITC Decision Making", Review of International Economics, Vol. 5, pp. 230-245.

Harimaya, K. and K. Kagitani (2006), "Trade Liberalization and Politics of Tariff Reduction", International Economy, No. 10, pp. 35-52.

Helpman, E. (1997), "Politics and trade policy", in D. M. Kreps and K. F. Wallis. eds., Advances in Economics and Econometrics: Theory and Applications, Vol. 1, Cambridge, Cambridge University Press, pp. 19-45.

Jackson, J. (1997), The World Trading System: Law and Policy of International Economic Relations, 2nd edition, Massachusetts, MIT press.

Kimura, F. (2001), "The Danger of Local Protectionism”, Journal of Japanese Trade \& Industry, November/December, pp. 8-11.

Komuro, N. (2001), "Japan's Safeguard Law and Practice”, Journal of World Trade, Vol. 35 , pp. 847-972.

Ministry of Economy, Trade and Industry, (2002), White Paper on International Trade 2002.

Moore, M. O. (1992a), "Rule or Politics?: an Empirical Analysis of ITC Antidumping Decisions", Economic Inquiry, Vol. 30, pp. 449-466.

Moore, M. O. (1992b), "Bureaucratic Trade-policy Decision as a Repeated Game", Journal of Institutional and Theoretical Economics, Vol. 148, pp. 607-627.

Moore, M. O. and Suranovic, S. M. (1992), "Lobbying vs. Administered Protection Endogenous Industry Choice and National Welfare -", Journal of International Economics, Vol. 32, pp. 289-303.

Olson, M. (1965), The Logic of Collective Action: Public Goods and the Theory of Groups, Cambridge, Harvard University Press.

Rodrik, D. (1995), "Political Economy of Trade Policy", in G. Grossman and Rogoff, K. eds., Handbook of International Economics vol.3, Amsterdam, North-Holland, pp. 1457-1494.

Rosendorff, B. P. and Milner, H. V. (2001), "The Optimal Design of International Trade Institutions: Uncertainty and Escape”, International Organization, Vol. 55, pp. 829857. 
Teramachi, N. (2004), "Financial Interests of Increases in Imports of Vegetables from China (Tyugoku Yasai Yunyu Zouka ni kakawaru Keizaiteki Rigai ni tsuite)", Kyoto Sangyo Daigaku Ronsyu -Syakaikagaku Keiretsu -, Vol. 21, pp. 829-857. (in Japanese)

Tharakan, P. K. M. (1991), "The Political Economy of Anti-dumping Undertakings in the European Communities", European Economic Review, Vol. 35, pp. 1341-1359. 